\title{
Endometriosis of the sciatic nerve
}

\author{
Alice Becker Teixeira', William A. Martins', Rui d'Ávila', Luciele Stochero', \\ Luciele Alberton', Sofia Bezerra', Alicia C.B. Romero 2, Paulo E. Freitas², Carlos Eduardo da Silva ${ }^{3}$
}

Endometriosis is a common disease, which affects $5-10 \%$ of women in fertile age ${ }^{1}$. It can affect multiple organs, such as ovaries, lungs, colon, nasal mucosa and brain $^{2}$. Endometriosis of the sciatic nerve is a rare presentation $^{3}$, manifesting as cyclic sciatica, parestesis and paresis with loss of deep tendon reflex. We cite a case of sciatica endometriosis and make a review of the literature.

\section{CASE}

A 26-year-old Caucasian woman exhibits intense pain and weakness in the lower left limb, which had progressed over the past nine years. She had no previous pregnancy and symptoms were worse during the menstrual period.

During examination, a dorsiflexion paresis of the left foot was notable. Magnetic resonance imagining (MRI) revealed an expansive process in the left sciatic nerve topography at gluteal topography.

The patient was referred for microsurgery, proceeding exeresis of a cystic lesion in the left sciatic nerve. Neuropathology analysis showed an endometrioma (Figure). The patient had no complications during the post-operative period.

During initial follow-up, dorsiflexion paresis in the left foot persisted. Post-operative MRI showed a cicatricial process, with no residual tumor. The eletroneuromiography (ENMG) displayed signs of a subacute denervatory process.

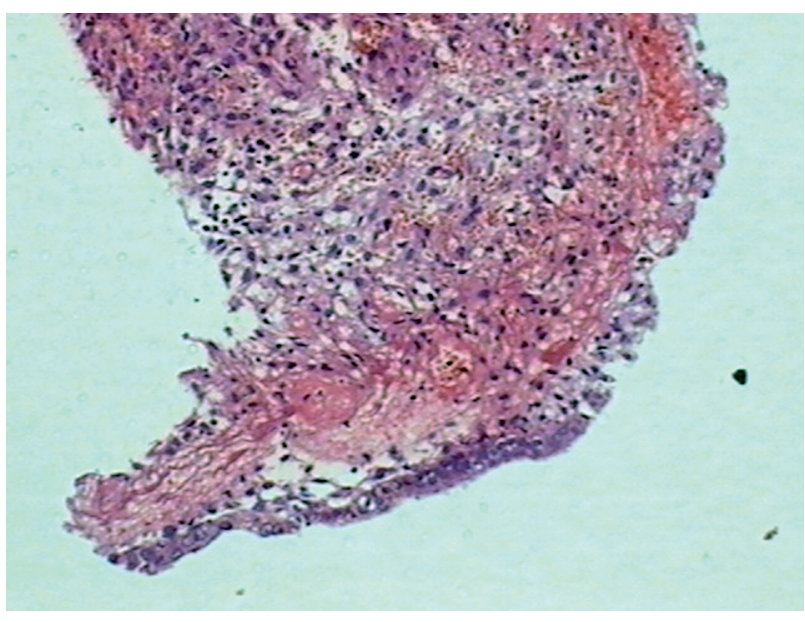

Figure. Hemorrhagic stroma with endometrial epithelium.

\section{DISCUSSION}

Endometriosis is a chronic recurrent pathology, characterized by proliferation of endometrial tissue outside the uterine cavity ${ }^{4}$. Typical locations include the ovaries, uterosacral ligaments, pelvic peritoneum, vagina ${ }^{2}$. Common clinical presentations are dysmenorrhea, infertility, dyspareunia, dysuria, or it can be asymptomatic.

The occurrence of endometrial tissue in the nerve root is a rare location, which was related for the first time in 1946 by Schlicke ${ }^{5}$. Cyclic sciatic is a rare symptom of endometriosis. Salazar-Grueso and Roos describe a mean 
interval of 3.7 years between the onset of symptoms and diagnosis. The typical symptom is cyclic sciatica related to the menstrual period, with painless intervals that become shorter each time until the pain becomes constant. Other symptoms are sensory loss, muscle weakness, reflex alterations, and a positive Lasègue's sign.

Presumably, endometriosis causes nerve damage by cyclical inflammation ${ }^{4}$. The ectopic uterine tissue once implanted in the nerve, advances aggressively the epineurium and perineurium.

Diagnosis can be made by an association of the symptoms to menstrual periods, and MRI findings. In the MRI it can be presented as a hiperintense solid or cystic mass. The signal intensity is due to the quantity and time of the bleeding. Further, the MRI can be useful in the differential diagnosis between a benign neurogenic tumor and the endometrioma. ENMG can demonstrate signs of denervation and a diminished conduction time, being useful to follow nerve recovery. However, a definitive diagnosis only can be made by the anatomopathological.

Endometriosis treatment involves pain control, hormone therapy and, for severe cases, surgical resection of the lesions ${ }^{1}$.
Endometriosis invading the sciatic nerve is a rare manifestation of a common disease. Early diagnosis and treatment is very important to minimize the nerve damage caused by recurrent cycles of bleeding and fibrosis, which are characteristics of endometriosis.

\section{REFERENCES}

1. Fraser IS. Recognising, understanding and managing endometriosis. J Hum Reprod Sci 2008;1:56-64.

2. Zager EL, Pfeifer SM, Brown MJ, et al. Catamenial mononeuropathy and radiculopathy: a treatable neuropathic disorder. J Neurosurg 1998; 88: 827-830.

3. Baker GS, Parsons WR, Welch JS. Endometriosis within the sheath of the sciatic nerve. J Neurosurg 1966;25:652-656.

4. Lu PY, Ory SJ. Endometriosis: current management. Mayo Clin Proc 1995; 70:453-463

5. Schlicke CP. Ectopic endometrial tissue in the thigh. JAMA 1946;132:445.

\section{ENDOMETRIOSE DO NERVO CIÁTICO}

Department of Neurosurgery and Skull Base Surgery, Hospital Ernesto Dornelles; Porto Alegre RS, Brazil: 'Medical Student; ${ }^{2} \mathrm{PhD} ;{ }^{3} \mathrm{MD}$.

Correspondence: Alice Becker Teixeira - Av. Protásio Alves 3563 / apto 23 90410-003 Porto Alegre RS - Brasil. E-mail: likabt@gmail.com

Received 29 May 2011. Received in final form 8 July 2011. Accepted 15 July 2011. 